\title{
Chronic lymphocytic leukemia: a clinical review including Korean cohorts
}

\author{
Young-Woo Jeon ${ }^{1,2,3}$ and Seok-Goo Cho ${ }^{1,2,3}$
}

\begin{abstract}
${ }^{1}$ Department of Hematology, Catholic Blood and Marrow Transplantation Center, ${ }^{2}$ Institute for Translational Research and Molecular Imaging, Catholic Institutes of Medical Science, ${ }^{3}$ Laboratory of Immune Regulation, Convergent Research Consortium for Immunologic Disease, College of Medicine, Seoul St. Mary's Hospital, The Catholic University of Korea, Seoul, Korea
\end{abstract}

Received: March 18, 2015 Accepted: June 10, 2015

\section{Correspondence to}

Seok-Goo Cho, M.D.

Department of Hematology,

Catholic Blood and Marrow

Transplantation Center, College of Medicine, Seoul St. Mary's Hospital, The Catholic University of Korea, 222 Banpo-daero, Seocho-gu, Seoul 06591, Korea

Tel: +82-2-2258-6053

Fax: +82-2-599-3589

E-mail: chosg@catholic.ac.kr

This article was presented in The 32nd World Congress of Internal Medicine 2014 .
Only 5th decade ago, chronic lymphocytic leukemia (CLL) was only recognized as disease group of presenting features like peripheral lymphocytosis, organomegaly including of splenomegaly. As understanding of disease biology and molecular diagnostic tools are getting improved gradually, characterization of variation in CLL's clinical courses was facilitated, resulting in better risk stratification and targeted treatments. Consequently multiple new targeted agents have been used in treatment of CLL, it makes improved clinical outcome. Rituximab containing chemoimmunotherapy (combination of rituximab, fludarabine, and cyclophosphamide) have shown better overall response rate and progression-free survival on fit patients' group in front-line setting, result in standard first-line therapeutic option for CLL. Furthermore, after introducing that the B-cell receptor is crucial for the evolution and progression of CLL, emerging treatments targeting highly activated surface antigens and oncogenic signaling pathways have been associated with several successes in recent decades. These include new anti-CD 20 monoclonal antibody (obinutuzumab), the bruton tyrosine kinase inhibitor (ibrutinib), the phosphatidylinositol 3-kinase inhibitor (idelalisib), and B-cell CLL/lymphoma 2 inhibitor (ABT-199 and ABT-263). So, we discuss not only general pathophysiology of CLL, but also rapidly advancing treatment strategies that are being studied or approved for treatment of CLL.

Keywords: Leukemia, lymphocytic, chronic, B-cell; Incidence; Investigational new drug application; Korean cohort

\section{INTRODUCTION}

Chronic lymphocytic leukemia (CLL) is common hematologic disease in Western societies with over 15,000 patients were diagnosed annually [1], but is very rare in Asian cohorts as well as Korea. The molecular diagnostic tools and variable understanding of the pathobiology of the disease have facilitated characterization of variations in the disease's clinical course, resulting in better risk stratification [2]. Consequently more precise targeting of therapy is possible, and the rapid evolution of treatment strategies for CLL and development of new drugs warrant a closer look into CLL. In consideration that the course of CLL typically has medical problems related to chronic infection, immunosuppressive status, autoimmune complication and surveillance of secondary malignancies, long-term relationship between medical practitioners and patients is need to solve those problems. Also, in Korea, the incidence of CLL has been gradually increased too and it is not the orphan disease 
any more in recent years, so we have plan to describe the generalized review about CLL, to intend to bring attention to take a profound interest in the field of CLL for the Korean medical doctors and researchers.

\section{CELLULAR ORIGIN OF CHRONIC LYMPHO- CYTIC LEUKEMIA}

There are significant geographical variations in the incidence of CLL. CLL is the most common adult B-cell leukemia of elderly patients in the Western world, but is less common among people of African or Asian origin [1]. Although the exact cellular origin of CLL remains a matter of controversy [2], approximately half of all CLL cases have unmutated $\mathrm{IgV}$ genes (uCLL). The remaining cases carry somatically mutated IgV genes (mCLL) [3]. This distinction is of biological interest and clinical relevance because UCLL is more aggressive, with a significantly shorter time from diagnosis to initial treatment [4].

Identification of the cellular origin of CLL is essential to elucidating the pathobiology of a tumor. Only then can the full natural course of the disease be revealed. It is also important to understand the dysregulation of gene expression and cellular functions [5]. The cellular origin of CLL as UCLL and mCLL is delineated by the absence or presence of $\mathrm{IgV}$ genes, respectively, from memory B-cells in a post-germinal center. However, based on a recent report on specific $\mathrm{IgV}$ gene rearrangements, a derivative of $\mathrm{uCLL}\left(\mathrm{CD}_{5}+, \mathrm{CD}_{27}-\mathrm{CD}_{3} 8^{\text {low }}\right)$ from conventional naive $\mathrm{B}$-cells was proposed. $\mathrm{mCLL}\left(\mathrm{CD}_{5}+\mathrm{C}-\right.$ D27+IgM+B-cell lymphoma [Bcl] $\left.6_{\text {mut }} \mathrm{IgVH}_{\text {mut }}\right)$ derives from a distinct, previously unrecognized B-cell subset from postgerminal centers [6].

\section{INCIDENCE OF CHRONIC LYMPHOCYTIC LEUKEMIA IN KOREA}

According to the crude incidence rate of non-Hodgkin lymphoma and the ratio of CLL in lymphoma, the crude incidence rate per 100,000 individuals was 0.11. In Korea, 56 patients are newly diagnosed with CLL annually. The crude prevalence rate of CLL is 0.61 per 100,000 . In total, 306 patients had prevalent CLL from the National Cancer Incidence Database (KNCI DB) in Korea (Table 1) [7]. The population of Korean patients have been limited, but according to a few reported data of single center, Korean patients diagnosed with CLL have more atypical immunophenotype with high frequencies of $\mathrm{FMC}_{7}+$ and strong presentation with $\mathrm{CD}_{22}+$ and more aggressive than that in Western populations $[8,9]$. And also considering an increasing incidence rate, and improvements in treatment, the incidence and prevalence rates are expected to be relatively high.

\section{CYTOGENETIC ABNORMALITY OF CHRONIC LYMPHOCYTIC LEUKEMIA}

Conventional metaphase cytogenetic techniques are difficult in CLL due to the very low proliferative activity of leukemia cells in vitro. Therefore, interphase cytogenetic analysis with fluorescence in situ hybridization (FISH) is the standard method to detect chromosomal abnormalities that may have prognostic significance. Cytogenetic abnormalities that can be detected by FISH are present in approximately $80 \%$ of patients with previously untreated CLL. In a German study, the most common abnormality was del(13q) (55\%), followed by del(11q)

Table 1. Epidemiology of chronic lymphocytic leukemia in Korea

\begin{tabular}{lcc}
\hline Variable & Western & Korea \\
\hline Annual incidence $\left(\right.$ per $\left.10^{5}\right)$ & 3.9 in Caucasian $(35$-fold), & 0.11 \\
Among all leukemias & 2.8 in Black $(25$-fold $)$ & $6 \%$ in Japan, $1.5 \%$ in Korea \\
Among all NHLs & $25 \%$ & $1.3 \%$ \\
Male:Female ratio & $5 \%-7 \%$ & $1.4: 1$ \\
Median age, yr & $2: 1$ & 59 \\
\hline
\end{tabular}

NHL, non-Hodgkin's lymphoma. 
Table 2. Prognosis of chronic lymphocytic leukemia according to the pattern of fluorescence in situ hybridization [11]

\begin{tabular}{lcc}
\hline Poor & Intermediate & Good \\
\hline $\operatorname{del}(11 q)-$ ATM & Normal & Del(13q) \\
$\operatorname{del}(17 \mathrm{p})-\mathrm{P}_{53}$ & $+12-$ CEP12 & (as a sole abnormality) \\
\hline
\end{tabular}

ATM, ataxia telangiectasia mutated; CEP12, centromeric probes targeting chromosome 12.

Table 3. Comparison of cytogenetic changes in chronic lymphocytic leukemia

\begin{tabular}{llccccccc}
\hline Source & Country & Number & Del(13q14) & Trisomy12 & Del(11q22) & Del(17p13) & IGH & Normal \\
\hline Haferlach et al. (2007) [13] & Germany & 500 & $287(57)$ & $68(14)$ & $60(12)$ & $35(7)$ & $30(6)$ & $74(14.8)$ \\
Grever et al. (2007) [14] & USA & 235 & $81(34.0)$ & $48(20.4)$ & $40(17.0)$ & $19(8.1)$ & $2(0.8)$ & $37(15.7)$ \\
Chena et al. (2003) [15] & Argentina & 57 & $36(63.2)$ & $20(35)$ & NA & $6(11)$ & NA & $11(19)$ \\
Arif et al. (1995) [16] & Japan & 42 & $12(29)$ & $8(19)$ & NA & NA & NA & $22(52)$ \\
Dong et al. (2011) [17] & China & 173 & $48(27.7)$ & $38(21.9)$ & $19(10.9)$ & $13(7.5)$ & $23(13.3)$ & NA \\
Wu et al. (2013) [18] & Taiwan & 83 & $38(45.8)$ & $17(20.5)$ & $11(13.3)$ & $9(10.8)$ & NA & $25(30.1)$ \\
Yoon et al. (2014) [9] & Korea & 48 & $6(12.5)$ & $14(29.1)$ & $6(12.5)$ & $5(10.4)$ & $6(12.5)$ & $22(45.8)$ \\
\hline
\end{tabular}

Values are presented as number (\%).

IGH, immunoglobulin heavy chain; NA, not applicable.

Table 4. Differential diagnosis between chronic lymphocytic leukemia and other B-cell lymphoma

\begin{tabular}{lccc}
\hline & MCL & FL & CLL/SLL \\
\hline CD5 & + & - & + \\
CD10 & - & + & - \\
CD23 & - & - & + \\
Light chain & $\lambda>\kappa$ & $\lambda<\kappa$ & $\lambda<\kappa$ \\
Cyclin D1 & + & - & - \\
\hline
\end{tabular}

MCL, mantle cell lymphoma; FL, follicular lymphoma; CLL, chronic lymphocytic leukemia; SLL, small lymphocytic lymphoma.

(18\%), trisomy 12 (16\%), and $\operatorname{del}(17 p)(7 \%)$ [10]. In the 2014 National Comprehensive Cancer Network guidelines, CLL was classified into three risk groups by FISH, with del(17p) as TP53 gene found to be the strongest predictor for poor prognosis (Tables 2 and 3) [9,11-18]. In contrast with the results of Western societies, trisomy 12 was more common abnormality, followed by del(13q14), del(11q22), and del(17p13) in Korean CLL data [9].

\section{CLINICAL MANIFESTATIONS AND DIAGNOSIS}

CLL is usually asymptomatic and found during a rou- tine blood test. However, some patients consult a physician because of painless swelling of the lymph nodes, often in the cervical area, which spontaneously enlarge and shrink but do not disappear. CLL is usually first suspected through the presence of lymphocytosis. According to the 1996 International Workshop on CLL update of the National Cancer Institute guidelines for CLL diagnosis and treatment, an absolute $\mathrm{B}$ lymphocyte count in the peripheral blood of $\geq 5,000 / \mu \mathrm{L}\left(5 \times 10^{9} / \mathrm{L}\right)$ sustained for longer than 3 months must be observed [19]. In the current system, patients with an absolute lymphocyte count less than $5,000 / \mu \mathrm{L}\left(5 \times 10^{9} / \mathrm{L}\right)$ are usually diagnosed with monoclonal B-cell lymphocytosis rather than CLL if they do not have palpably enlarged lymph nodes, spleen, and/or liver [20]. Immunophenotyping, usually by flow cytometry, is a key component to the diagnosis of CLL [21]. Major immunophenotypic analyses of CLL show the expression of B cell-associated antigens, including CD19, CD2o (usually weak), and $\mathrm{CD}_{23}$, with characteristic expression of $\mathrm{CD}_{5}$, a common T-cell antigen [19]. In addition, the $\kappa$ or $\lambda$ light chain restriction pattern and surface IgM and IgD expressions are decreased. Immunohistochemistry of lymph node biopsies show that they were positive for $\mathrm{CD}_{5}, \mathrm{CD}_{2} \mathrm{O}$, and $\mathrm{CD}_{23}$, and negative for $\mathrm{CD}_{3}, \mathrm{CD} 10$, and cyclin $\mathrm{D}_{1}$ (Table 4). Because of CD5 expression in CLL, mantle cell 
Table 5. Binet staging system [23]

\begin{tabular}{llcc}
\hline Stage & \multicolumn{1}{c}{ Definition } & Survival median, yr & Patient, \% \\
\hline A & $\mathrm{Hb} \geq 10 \mathrm{~g} / \mathrm{dL}$, PLT $\geq 100,000 / \mathrm{mm}^{3},<3$ enlarged lymphoid areas & 12 & 60 \\
B & $\mathrm{Hb} \geq 10 \mathrm{~g} / \mathrm{dL}, \mathrm{PLT} \geq 100,000 / \mathrm{mm}^{3}, \geq 3$ enlarged areas & 7 & 30 \\
$\mathrm{C}$ & $\mathrm{Hb}<10 \mathrm{~g} / \mathrm{dL}, \mathrm{PLT}<100,000 / \mathrm{mm}^{3}$, any number of enlarged LN areas & $2-4$ & 10 \\
\hline
\end{tabular}

Areas of involvement considered for staging are as follows: (1) head and neck, including the Waldeyer's ring (this counts as one area, even if more than one group of nodes are enlarged); (2) axillae (involvement of both axillae counts as one area); (3) groins, including superficial femoral (involvement of both groins counts as one area); (4) palpable spleen; (5) palpable liver (clinically enlarged).

$\mathrm{Hb}$, hemoglobin; PLT, platelet; LN, lymph node.

Table 6. Rai staging system $[11,24]$

\begin{tabular}{|c|c|c|c|}
\hline Stage & Definition & Risk & Survival, yr \\
\hline o & Lymphocytosis, lymphocytes in blood $>15,000 / \mu \mathrm{L}$ and $>40 \%$ lymphocytes in $\mathrm{BM}$ & Low & $>10$ \\
\hline I & Stage o with enlarged nodes & Intermediate & 9 \\
\hline II & Stage o-I with splenomegaly or hepatomegaly or both & Intermediate & 5 \\
\hline III & Stage o-II with $\mathrm{Hb}<11 \mathrm{~g} / \mathrm{dL}$ or Hct $<33 \%$ & High & 2 \\
\hline IV & Stage o-III with PLT $<100,000 / \mathrm{mm}^{3}$ & High & 2 \\
\hline
\end{tabular}

$\mathrm{BM}$, bone marrow; Hb, hemoglobin; Hct, hematocrit; PLT, platelet.

Table 7. Poor prognostic factor for chronic lymphocytic leukemia

\begin{tabular}{|c|c|}
\hline No. & Poor prognostic factors \\
\hline 1 & Advanced stage \& age at diagnosis \\
\hline 2 & Male sex \\
\hline 3 & Diffuse pattern of BM infiltration \\
\hline 4 & Short lymphocyte doubling time \\
\hline 5 & High expression of $\mathrm{Ki} 67$, p27 \\
\hline 6 & High serum level of $\beta 2 \mathrm{MG}, \mathrm{TK}, \mathrm{sCD} 23, \mathrm{TNF} \alpha$ \\
\hline 7 & $\begin{array}{l}\text { Poor risk cytogenetics: 17p \& 11q del, } \\
\text { complex karyotype }\end{array}$ \\
\hline 8 & High level of $\mathrm{CD}_{3} 8$ \& ZAP-70 expression \\
\hline 9 & High level of expression of lipoprotein lipase \\
\hline 10 & $\begin{array}{l}\text { Unmutated IgVH gene status, altered micro RNA } \\
\text { expression }\end{array}$ \\
\hline 11 & $\begin{array}{l}\text { Poor response to therapy or short duration of } \\
\text { response }\end{array}$ \\
\hline
\end{tabular}

BM, bone marrow; $\beta 2 \mathrm{MG}, \beta 2$-microglobulin; TK, tyrosine kinase; TNF $\alpha$, tumor necrosis factor $\alpha$; ZAP-70, $\zeta$-chain-associated protein kinase 70; IgVH, immunoglobulin heavychain variable-region.

lymphoma may mimic CLL. However, neoplastic cells from mantle cell lymphoma stain strongly for cyclin D1 and surface membrane immunoglobulin, have a $t(11 ; 14)$ chromosomal abnormality, and are CD23-negative. In contrast, malignant cells in CLL are cyclin D1-negative and often CD23-positive [22].

\section{CLINICAL STAGING}

The two staging systems for CLL are the Binet staging system, proposed in 1981 (Table 5) [23], and the Rai staging system, suggested in 1975 (Table 6) [24]. The Binet staging system is used more frequently.

\section{PROGNOSTIC FACTORS FOR CHRONIC LYM- PHOCYTIC LEUKEMIA}

CLL patients in the high-risk group include those who are refractory to fludarabine chemotherapy, who fail to achieve a response or show disease progression within 24 months of rituximab-based combination chemotherapy, or who have a TP53 mutation or del(17p). These highrisk patients have less than 36 months of overall survival after chemotherapy. We routinely performed FISH to detect chromosomal aberrations that are strong poor prognostic markers (Table 7). The identification of new 
Table 8. A new prognostic model based on integrated and cytogenetic analysis [25]

\begin{tabular}{llcc}
\hline Risk subgroup & \multicolumn{1}{c}{ Integration of mutations \& cytogenetic lesion } & 5-Year survival, \% & 10-Year survival, \% \\
\hline High & TP53 and/or BIRC3 abnormalities & 50.9 & 29 \\
Intermediate & NOTCH1 and/or SF3 3 1 mutations and/or del(11q22-q23) & 65.9 & 37 \\
Low & +12 and no genetic mutations & 77.6 & 57 \\
Very low & Del(13q14) only & 86.9 & 69.3 \\
\hline
\end{tabular}

Table 9. Guidelines for chronic lymphocytic leukemia management [34]

\begin{tabular}{|c|c|c|c|}
\hline Patient's group & Condition & Status & Proper regimen \\
\hline \multirow[t]{3}{*}{$\begin{array}{l}\text { Newly diagnosed CLL or untreated } \\
\text { CLL requiring therapy }\end{array}$} & \multirow[t]{2}{*}{ Significant comorbidity } & No & $\mathrm{R}-\mathrm{FC}$ regimen \\
\hline & & Yes & Alkylating agents \pm anti-CD2O antibody \\
\hline & 17p deleted & Alemtuzu & ab followed by alloHSCT (in proper case) \\
\hline \multirow[t]{3}{*}{ Relapsed CLL requiring therapy } & \multirow[t]{2}{*}{ Remission duration } & $>2$ years & Repeat initial therapy \\
\hline & & $\leq 2$ years & Consider another option (alemtuzumab or trials) \\
\hline & 17p deleted & \multicolumn{2}{|c|}{ Alemtuzumab followed by alloHSCT (in proper case) } \\
\hline
\end{tabular}

CLL, chronic lymphocytic leukemia; R-FC, rituximab + fludarabine + cyclophosphamide; alloHSCT, allogenetic hematopoietic stem cell transplantation.

genetic lesions in CLL has prompted the development of a comprehensive and dynamic prognostic algorithm. This algorithm considers gene mutations, chromosomal abnormalities, and their changes during recent clonal evolution (Table 8) [25]. However, this model requires both additional verification and a solution to its high cost.

\section{TREATMENT OPTIONS}

CLL is an extremely heterogeneous disease and most patients have early stage disease at the time of diagnosis. Therapy is indicated for patients with "active disease," as manifested by an advanced stage, high tumor burden, disease-related "B" symptoms, or repeated infections $[26,27]$.

\section{Previously untreated patients}

The selection of therapeutic options for previously untreated patients should consider the patient's age, comorbidities, performance status, and genetic testing, especially for del(17p). In CLL without comorbidities or del(17p), the standard regimen is rituximab, fludarabine, and cyclophosphamide (R-FC). The R-FC regimen has higher rates of overall survival, complete response (70\%), longer median progression-free survival, excellent induction effect, and minimal residual disease [28-30]. However, neutropenia and infusion-related toxicities were more common in patients receiving this regimen [31]. In elderly patients (> 70 years), those with poor performance status, or unavailable hospitalization, a combination regimen of rituximab and chlorambucil is the best option for first-line treatment [32]. Unfortunately, in Korea, only chlorambucil single method is available by Korean Health Insurance Review \& Assessment Service. In high risk patients with $\operatorname{del}(17 p)$ or TP53 mutations, alemtuzumab therapy followed by allogeneic stem cell transplantation is recommended (Table 9) [33,34].

\section{Relapsed or refractory patients}

For patients relapsing after or refractory to first-line therapy, treatment options depend on the duration of the response following first-line treatment [35]. In CLL patients with a time to treatment failure of 2 years or more, retreatment with the same regimen used as firstline therapy is recommended. However, in patients with relapsed disease within 2 years of the initial therapy, the suggested treatment options are alemtuzumab monotherapy, a combination of rituximab and bendamustine, other clinical trials (ibrutinib, idelalisib, and ABT-199), 
or allogeneic stem cell transplantation (Table 9).

\section{New drugs}

CLL is the most common leukemia in adults in Western countries, accounting for approximately $30 \%$ of all leukemia in the United States [36]. A broad range of novel agents with different mechanisms of action are being evaluated in clinical trials, with some already showing both efficacy and a favorable safety profile. These include combinations of agents already used in CLL therapy, agents approved for other diseases (such as lenalidomide and dasatinib), new antibodies (such as anti-CD37 antibodies), and other novel agents (such as flavopiridol, bruton tyrosine kinase (BTK) inhibitors other than ibrutinib, phosphatidylinositol 3-kinase inhibitors other than idelalisib, and Bcl-2 antagonists [37-39].

New drugs for CLL are divided into two groups: one group targets the $\mathrm{B}$ cell receptor (BCR) signaling pathway and the other, leukemia cell-specific molecular markers. Essential components of BCR signaling pathway include Lyn, Syk, and BTK. Ibrutinib (PCI-32765) as BTK inhibitor was associated with a high frequency of durable remissions (overall survival, 88\%) in patients with relapsed or refractory CLL and small lymphocytic lymphoma. This included patients with high-risk genetic lesions (28 patients; overall survival, 68\%) [40]. A combination of idelalisib and rituximab, compared with placebo or rituximab alone, significantly improved progression-free survival, response rate, and overall survival among patients with relapsed CLL who are less suitable for chemotherapy [41]. ABT-199, a selective Bcl-2 blocker that neutralizes Bcl-2 with high selectivity over Bcl-XL, also shows good response without thrombocytopenia, unlike navitoclax, which causes severe thrombocytopenia [42]. The representative new drugs mentioned above, ibrutinib, idelalisib, and ABT-199, are oral agents. More amounts of promising clinical data are expected in the future. A combination of an anti-CD2o antibody with chemotherapy improved outcomes in patients with CLL and comorbidities. In this patient population, obinutuzumab was superior to rituximab when in combination with chlorambucil (Fig. 1) [43,44].

\section{Allogeneic hematopoietic stem cell transplantation}

Patients with CLL have the general characteristics with old age-onset and the relatively benign course of the

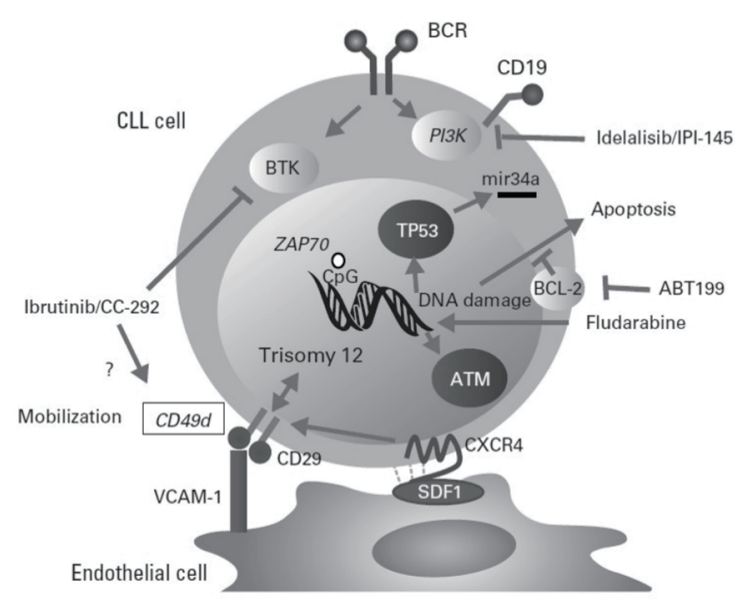

Figure 1. Cellular markers and new drugs in chronic lymphocytic leukemia (CLL). A large number of cellular biomarkers have been found to correlate with prognosis in patients. Biomarkers can be grouped into the following functional categories. First, genetic lesions like loss of function of the DNA-damage response by $\mathrm{TP}_{53}$ or ATM (ataxia telangiectasia mutated) (i.e., $\operatorname{del}(17 \mathrm{p}), \operatorname{del}(11 \mathrm{q})$ ), especially with respect to DNA-damaging chemotherapy like fludarabine. Second, epigenetic modifications, for example, DNA methylation of $\mathrm{CpG}$ dinucleotides in the ZAP-70 ( $\zeta$-chain-associated protein kinase 70) gene as a surrogate marker for the immunoglobulin heavy-chain variable region (IGHV) hypermutation status. Third, surface markers like CD49d that correlate not only with prognosis, but also with genetic aberrations like trisomy 12 are possibly involved in mobilization and homing of CLL cells. Fourth, levels of microRNA genes like miR34a as readout for activity of TP53. Soluble serum markers of prognostic relevance such as levels of thymidine kinase and $\beta 2$-microglobulin are not shown. With the advent of novel therapeutic compounds targeting bruton tyrosine kinase (BTK) or phosphatidylinositol 3-kinase $\left(\mathrm{PI}_{3} \mathrm{~K}\right)$, the significance of current biomarkers will have to be re-evaluated. Adapted from Mertens et al. [44], with permission from American Society of Clinical Oncology. BCR, B cell receptor; Bcl-2, B-cell lymphoma 2; CXCR4, chemokine (C-X-C motif) receptor 4; VCAM-1, vascular cell adhesion molecule 1; SDF1, stromal cell-derived factor 1.

disease in the majority of patients. So, only a selected subset is considered for aggressive treatments such as hematopoietic stem cell transplantation (HSCT). CLL transplantation criteria include a non-response or relapse within 12 months after purine analog-containing therapy, relapse within 24 months after purine-analog combination therapy or similarly efficacious therapy (autologous stem cell transplantation), and $\operatorname{del}(17)$ or TP53 deletion/mutations requiring therapy [45]. 
Table 10. Summary of CD19-specific CAR-T cell therapy in a patient with refractory chronic lymphocytic leukemia

\begin{tabular}{ll}
\hline Time & \multicolumn{1}{c}{ Therapy } \\
\hline 1996 & Initial diagnosis: CLL stage I \\
2002 & $\begin{array}{l}\text { PD of CLL } \rightarrow \text { progressive leukocytosis and adenopathy } \rightarrow \text { treated with } 2 \text { cycles of rituximab \& } \\
\text { fludarabine } \rightarrow \text { PR }\end{array}$ \\
2006 & PD $\rightarrow$ cycles of rituximab \& fludarabine $\rightarrow$ PR \\
2009 & PD $\rightarrow$ cytogenetics: del 17p (3/15), FISH: del 17p (170/200), TP 53 inactivation \\
2009 Dec & Auto-T cells: leukapheresis and cryopreservation \\
& Alemtuzumab for 11 weeks $\rightarrow$ PR \\
$2010 ~ J u l ~$ & Phase I trial of CD19-specific CAR-T cell therapy \\
\hline
\end{tabular}

CAR-T cell, chimeric antigen receptor T cell; CLL, chronic lymphocytic leukemia; PD, progressive disease; PR, partial response; FISH, fluorescence in situ hybridization.

Table 11. Response evaluation criteria for chronic lymphocytic leukemia treatment

\begin{tabular}{|c|c|c|c|c|}
\hline Parameter & Complete response (CR) & Partial response (PR) & Progressive disease (PD) & Stable disease (SD) \\
\hline \multicolumn{5}{|l|}{ Physical examination } \\
\hline Lymphadenopathy & None $>1.5 \mathrm{~cm}$ & Decrease $\geq 50 \%$ & $\begin{array}{l}\text { Increase } \geq 50 \% \text { or } \\
\text { appearance of any new } \\
\text { lesion }\end{array}$ & Change of $-49 \%$ to $49 \%$ \\
\hline $\begin{array}{l}\text { Hepatomegaly/ } \\
\text { splenomegaly }\end{array}$ & Normal size & Decrease $\geq 50 \%$ & $\begin{array}{l}\text { Increase } \geq 50 \% \text { or } \\
\text { new enlargement when } \\
\text { previously normal }\end{array}$ & Change of $-49 \%$ to $49 \%$ \\
\hline $\begin{array}{l}\text { Constitutional } \\
\text { symptom }\end{array}$ & None & Any & Any & Any \\
\hline \multicolumn{5}{|l|}{ Laboratory data } \\
\hline $\begin{array}{l}\text { Polymorphonuclear } \\
\text { leukocytes }\end{array}$ & $\begin{array}{l}>1.5 \times 10^{9} / \mathrm{L} \text { without need } \\
\text { for exogenous growth } \\
\text { factors }\end{array}$ & $\begin{array}{l}>1.5 \times 10^{9} / \mathrm{L} \text { or }>50 \% \\
\text { improvement over } \\
\text { baseline without need } \\
\text { for exogenous growth } \\
\text { factors }\end{array}$ & Any & Any \\
\hline $\begin{array}{l}\text { Circulating clonal } \\
\text { B-lymphocytes }\end{array}$ & None & $\begin{array}{c}\text { Decrease } \geq 50 \% \\
\text { over baseline }\end{array}$ & $\begin{array}{l}\text { Increase } \geq 50 \% \text { over } \\
\text { baseline }\end{array}$ & Change of $-49 \%$ to $49 \%$ \\
\hline Platelet counts & $\begin{array}{l}>100 \times 10^{9} / \mathrm{L} \text { without } \\
\text { need for exogenous } \\
\text { growth factors }\end{array}$ & $\begin{array}{l}>100 \times 10^{9} / \mathrm{L} \text { or increase } \\
\geq 50 \% \text { over baseline }\end{array}$ & $\begin{array}{l}\text { Decrease } \geq 50 \% \text { from } \\
\text { baseline or to }<100 \times \\
10^{9} / \mathrm{L} \text { secondary to CLL }\end{array}$ & Change of $-49 \%$ to $49 \%$ \\
\hline Hemoglobin & $\begin{array}{l}>110 \mathrm{~g} / \mathrm{L} \text { (untrasnfused } \\
\text { and without need for } \\
\text { exogenous } \\
\text { erythropoietin) }\end{array}$ & $\begin{array}{l}>110 \mathrm{~g} / \mathrm{L} \text { or increase } \geq \\
50 \% \text { over baseline }\end{array}$ & $\begin{array}{l}\text { Decrease of }>20 \mathrm{~g} / \mathrm{L} \\
\text { from baseline or to } \\
<100 \mathrm{~g} / \mathrm{L} \text { secondary } \\
\text { to CLL }\end{array}$ & $\begin{array}{l}\text { Increase } \leq 110 \mathrm{~g} / \mathrm{L} \text { or } \\
<50 \% \text { over baseline, } \\
\text { or decrease }<20 \mathrm{~g} / \mathrm{L}\end{array}$ \\
\hline Bone marrow & $\begin{array}{l}\text { Normocellular for age, } \\
<30 \% \text { lymphocytes, no } \\
\text { B-lymphoid nodules, } \\
\text { hypocellular marow } \\
\text { with no clonal infiltrates } \\
\text { defines CRi }\end{array}$ & $\begin{array}{l}\text { No BM requirement to } \\
\text { document } \mathrm{PR}\end{array}$ & $\begin{array}{l}\text { No BM requirement to } \\
\text { document } \mathrm{PD}\end{array}$ & $\begin{array}{l}\text { No BM requirement } \\
\text { to document SD }\end{array}$ \\
\hline
\end{tabular}

Adopted from Hallek et al. [19], with permission from American Society of Hematology.

CLL, chronic lymphocytic leukemia; BM, bone marrow; CRi, incomplete blood count recovery. 


\section{Cell therapy}

A pilot clinical trial in patients with relapsed/refractory p53-deficient CLL was performed using CD19-specific chimeric antigen receptor T-cell therapy [46]. This therapy regimen is strongly expected to provide an alternative treatment option in CLL patients who are refractory to conventional treatment (Table 10).

\section{Tumor response assessment}

Tumor response assessments for CLL are distinctive compared to other lymphoma subtypes. Response assessment involves both tumor burden and evaluation of hematopoietic function. For complete remission, all of the following criteria must be met without cancer related- constitutional symptoms. For partial response, at least two of the following group A criteria must be met over at least 2 months and at least one of the group B criteria must be met (Table 11) [19].

\section{RARE COMPLICATIONS OF CHRONIC LYM- PHOCYTIC LEUKEMIA}

\section{Infectious complications}

Patients with CLL are susceptible to infectious events due to a reduction in immunoglobulin levels, decreased function of T-cells, other lymphocytes, and monocytes. Administration of immunoglobulin, prophylactic bactrim, and vaccination are necessary to minimize infectious events [47].

\section{Richter syndrome}

Approximately $2 \%$ to $10 \%$ of patients with CLL will develop Richter syndrome during transformation to diffuse large B-cell lymphoma or Hodgkin lymphoma during the course of the disease [48]. The cumulative incidence increases by approximately o.1\% per year. Diagnostic clues include increased serum lactate dehydrogenase, B symptoms, and rapidly enlarged lymph nodes. Biopsy confirmation is needed, and positron emission tomography-computed tomography is helpful in selecting the target for biopsy. The median time to development of Richter syndrome after CLL diagnosis is 1.8 to 5 years [49]. Prognosis is poor, with an overall survival of 5 to 8 months from initial diagnosis [50]. Patients with Richter syndrome should be treated with combination chemoimmunotherapy, such as R-CHOP (rituximab, cyclophosphamide, doxorubicin, vincristine, and prednisone), HyperCVAD (cyclophosphamide, vincristine, doxorubicin, and dexamethasone), and OFAR (oxaliplatin, fludarabine, cytarabine, and rituximab) regimens [51]. Early allogeneic HSCT has shown promising results with Richter syndrome in younger patients [51].

\section{Autoimmune cytopenias}

Autoimmune hemolytic anemia (AIHA) is the most common form of autoimmune cytopenia, with an incidence rate of $4.3 \%$ to $9.7 \%$. Patients with advanced disease, unmutated immunoglobulin heavy-chain variable region, and high expression of $\zeta$-chain-associated protein kinase 70 (ZAP-70) are also at high risk for developing AIHA [52]. Purine analog-based therapy has been associated with AIHA. Recent studies have also reported a higher incidence of AIHA in patients treated with fludarabine or chlorambucil compared to those receiving R-FC or FC regimens [52,53]. Laboratory results found anemia followed by thrombocytopenia. Clinically autoimmune cytopenia is considered when it appears in sudden hemolytic events, thrombocytopenia of unknown origin without septicemia, or splenomegaly. In most cases, AIHA can be managed with corticosteroids. Intravenous immunoglobulin, cyclosporine, and splenectomy may be used in steroid-refractory cases. If the cause of autoimmune cytopenia is a monotherapy, especially fludarabine monotherapy, the chemotherapy regimen should be changed immediately to a combination regimen [54].

\section{CONCLUSIONS}

In Korea, although there are small numbers of patients diagnosed with CLL, the incidence of CLL is gradually increasing. This increase appears to be related with the rapid aging of society and the westernization of Korean lifestyles.

As the rapid evolution of treatment strategies for CLL and development of new drugs warrant a closer look into CLL, Korean medical doctors and researchers should take a profound interest in the field of CLL. 


\section{Conflict of interest}

No potential conflict of interest relevant to this article was reported.

\section{REFERENCES}

1. Dores GM, Anderson WF, Curtis RE, et al. Chronic lymphocytic leukaemia and small lymphocytic lymphoma: overview of the descriptive epidemiology. Br J Haematol 2007;139:809-819.

2. Zenz T, Mertens D, Kuppers R, Dohner H, Stilgenbauer S. From pathogenesis to treatment of chronic lymphocytic leukaemia. Nat Rev Cancer 2010;10:37-50.

3. Damle RN, Wasil T, Fais F, et al. Ig V gene mutation status and $\mathrm{CD}_{3} 8$ expression as novel prognostic indicators in chronic lymphocytic leukemia. Blood 1999;94:1840-1847.

4. Rassenti LZ, Jain S, Keating MJ, et al. Relative value of ZAP-70, $\mathrm{CD}_{3} 8$, and immunoglobulin mutation status in predicting aggressive disease in chronic lymphocytic leukemia. Blood 2008;112:1923-1930.

5. Kuppers R, Klein U, Hansmann ML, Rajewsky K. Cellular origin of human B-cell lymphomas. N Engl J Med 1999;341:1520-1529.

6. Forconi F, Potter KN, Wheatley I, et al. The normal IGHV1-69-derived B-cell repertoire contains stereotypic patterns characteristic of unmutated CLL. Blood 2010;115:71-77.

7. Jung KW, Won YJ, Kong HJ, Oh CM, Seo HG, Lee JS. Cancer statistics in Korea: incidence, mortality, survival and prevalence in 2010. Cancer Res Treat 2013;45:1-14.

8. Jang MA, Yoo EH, Kim K, et al. Chronic lymphocytic leukemia in Korean patients: frequent atypical immunophenotype and relatively aggressive clinical behavior. Int J Hematol 2013;97:403-408.

9. Yoon JH, Kim Y, Yahng SA, et al. Validation of Western common recurrent chromosomal aberrations in Korean chronic lymphocytic leukaemia patients with very low incidence. Hematol Oncol 2014;32:169-177.

10. Dohner H, Stilgenbauer S, Benner A, et al. Genomic aberrations and survival in chronic lymphocytic leukemia. N Engl J Med 2000;343:1910-1916.

11. Zelenetz AD, Gordon LI, Wierda WG, et al. Non-Hodgkin's lymphomas, version 4.2014. J Natl Compr Canc Netw 2014;12:1282-1303.

12. Oscier D, Wade R, Davis Z, et al. Prognostic factors identi- fied three risk groups in the LRF CLL4 trial, independent of treatment allocation. Haematologica 2010;95:1705-1712.

13. Haferlach C, Dicker F, Schnittger S, Kern W, Haferlach T. Comprehensive genetic characterization of CLL: a study on 506 cases analysed with chromosome banding analysis, interphase FISH, $\operatorname{IgV}(\mathrm{H})$ status and immunophenotyping. Leukemia 2007;21:2442-2451.

14. Grever MR, Lucas DM, Dewald GW, et al. Comprehensive assessment of genetic and molecular features predicting outcome in patients with chronic lymphocytic leukemia: results from the US Intergroup Phase III Trial E2997. J Clin Oncol 2007;25:799-804.

15. Chena C, Arrossagaray G, Scolnik M, Palacios MF, Slavutsky I. Interphase cytogenetic analysis in Argentinean B-cell chronic lymphocytic leukemia patients: association of trisomy 12 and del(13q14). Cancer Genet Cytogenet 2003;146:154-160.

16. Arif M, Tanaka K, Asou H, Ohno R, Kamada N. Independent clones of trisomy 12 and retinoblastoma gene deletion in Japanese B cell chronic lymphocytic leukemia, detected by fluorescence in situ hybridization. Leukemia 1995;9:1822-1827.

17. Dong HJ, Zhou LT, Zhu DX, et al. The prognostic significance of TP53 mutations in Chinese patients with chronic lymphocytic leukemia is independent of del(17p13). Ann Hematol 2011;90:709-717.

18. Wu SJ, Lin CT, Huang SY, et al. Chromosomal abnormalities by conventional cytogenetics and interphase fluorescence in situ hybridization in chronic lymphocytic leukemia in Taiwan, an area with low incidence: clinical implication and comparison between the West and the East. Ann Hematol 2013;92:799-806.

19. Hallek M, Cheson BD, Catovsky D, et al. Guidelines for the diagnosis and treatment of chronic lymphocytic leukemia: a report from the International Workshop on Chronic Lymphocytic Leukemia updating the National Cancer Institute-Working Group 1996 guidelines. Blood 2008;111:5446-5456.

20. Rawstron AC, Bennett FL, O'Connor SJ, et al. Monoclonal B-cell lymphocytosis and chronic lymphocytic leukemia. N Engl J Med 2008;359:575-583.

21. Rawstron AC, Villamor N, Ritgen M, et al. International standardized approach for flow cytometric residual disease monitoring in chronic lymphocytic leukaemia. Leukemia 2007;21:956-964.

22. DiRaimondo F, Albitar M, Huh Y, et al. The clinical and 
diagnostic relevance of $\mathrm{CD} 23$ expression in the chronic lymphoproliferative disease. Cancer 2002;94:1721-1730.

23. Binet JL, Auquier A, Dighiero G, et al. A new prognostic classification of chronic lymphocytic leukemia derived from a multivariate survival analysis. Cancer 1981;48:198206.

24. Rai KR, Sawitsky A, Cronkite EP, Chanana AD, Levy RN, Pasternack BS. Clinical staging of chronic lymphocytic leukemia. Blood 1975;46:219-234.

25. Rossi D, Rasi S, Spina V, et al. Integrated mutational and cytogenetic analysis identifies new prognostic subgroups in chronic lymphocytic leukemia. Blood 2013;121:14031412.

26. CLL Trialists' Collaborative Group. Chemotherapeutic options in chronic lymphocytic leukemia: a meta-analysis of the randomized trials. J Natl Cancer Inst 1999;91:861868.

27. The French Cooperative Group on Chronic Lymphocytic Leukemia. Effects of chlorambucil and therapeutic decision in initial forms of chronic lymphocytic leukemia (stage A): results of a randomized clinical trial on 612 patients. Blood 1990;75:1414-1421.

28. Wierda WG, Kipps TJ, Durig J, et al. Chemoimmunotherapy with O-FC in previously untreated patients with chronic lymphocytic leukemia. Blood 2011;117:6450-6458.

29. Tam CS, Wolf M, Prince HM, et al. Fludarabine, cyclophosphamide, and rituximab for the treatment of patients with chronic lymphocytic leukemia or indolent non-Hodgkin lymphoma. Cancer 2006;106:2412-2420.

30. Foon KA, Boyiadzis M, Land SR, et al. Chemoimmunotherapy with low-dose fludarabine and cyclophosphamide and high dose rituximab in previously untreated patients with chronic lymphocytic leukemia. J Clin Oncol 2009;27:498-503.

31. Byrd JC, Peterson BL, Morrison VA, et al. Randomized phase 2 study of fludarabine with concurrent versus sequential treatment with rituximab in symptomatic, untreated patients with B-cell chronic lymphocytic leukemia: results from Cancer and Leukemia Group B 9712 (CALGB 9712). Blood 2003;101:6-14.

32. Hillmen P, Gribben JG, Follows GA, et al. Rituximab plus chlorambucil as first-line treatment for chronic lymphocytic leukemia: final analysis of an open-label phase II study. J Clin Oncol 2014;32:1236-1241.

33. Pettitt AR, Jackson R, Carruthers S, et al. Alemtuzumab in combination with methylprednisolone is a highly ef- fective induction regimen for patients with chronic lymphocytic leukemia and deletion of TP53: final results of the national cancer research institute CLL206 trial. J Clin Oncol 2012;30:1647-1655.

34. Hillmen P. Using the biology of chronic lymphocytic leukemia to choose treatment. Hematology Am Soc Hematol Educ Program 2011;2011:104-109.

35. Keating MJ, Wierda WG, Tam CS, et al. Long term outcome following treatment failure of FCR chemoimmunotherapy as initial therapy for chronic lymphocytic leukemia. Blood 2009;114:2381.

36. Siegel R, Ma J, Zou Z, Jemal A. Cancer statistics, 2014. CA Cancer J Clin 2014;64:9-29.

37. O'Brien S, Moore JO, Boyd TE, et al. Randomized phase III trial of fludarabine plus cyclophosphamide with or without oblimersen sodium (Bcl-2 antisense) in patients with relapsed or refractory chronic lymphocytic leukemia. J Clin Oncol 2007;25:1114-1120.

38. Byrd JC, Pagel JM, Awan FT, et al. A phase 1 study evaluating the safety and tolerability of otlertuzumab, an anti-CD37 mono-specific ADAPTIR therapeutic protein in chronic lymphocytic leukemia. Blood 2014;123:1302-1308.

39. Burger JA, Keating MJ, Wierda WG, et al. Safety and activity of ibrutinib plus rituximab for patients with highrisk chronic lymphocytic leukaemia: a single-arm, phase 2 study. Lancet Oncol 2014;15:1090-1099.

40. Byrd JC, Furman RR, Coutre SE, et al. Targeting BTK with ibrutinib in relapsed chronic lymphocytic leukemia. $\mathrm{N}$ Engl J Med 2013;369:32-42.

41. Furman RR, Sharman JP, Coutre SE, et al. Idelalisib and rituximab in relapsed chronic lymphocytic leukemia. $\mathrm{N}$ Engl J Med 2014;370:997-1007.

42. Green DR, Walczak H. Apoptosis therapy: driving cancers down the road to ruin. Nat Med 2013;19:131-133.

43. Goede V, Fischer K, Busch R, et al. Obinutuzumab plus chlorambucil in patients with CLL and coexisting conditions. N Engl J Med 2014;370:1101-1110.

44. Mertens D, Stilgenbauer S. Prognostic and predictive factors in patients with chronic lymphocytic leukemia: relevant in the era of novel treatment approaches? J Clin Oncol 2014;32:869-872.

45. Brown JR. The treatment of relapsed refractory chronic lymphocytic leukemia. Hematology Am Soc Hematol Educ Program 2011;2011:110-118.

46. Porter DL, Levine BL, Kalos M, Bagg A, June CH. Chimeric antigen receptor-modified $\mathrm{T}$ cells in chronic lym- 
phoid leukemia. N Engl J Med 2011;365:725-733.

47. Chapel H, Dicato M, Gamm H, et al. Immunoglobulin replacement in patients with chronic lymphocytic leukaemia: a comparison of two dose regimes. Br J Haematol 1994;88:209-212.

48. Rossi D, Gaidano G. Richter syndrome: molecular insights and clinical perspectives. Hematol Oncol 2009;27:110.

49. Parikh SA, Rabe KG, Call TG, et al. Diffuse large B-cell lymphoma (Richter syndrome) in patients with chronic lymphocytic leukaemia (CLL): a cohort study of newly diagnosed patients. Br J Haematol 2013;162:774-782.

50. Chigrinova E, Rinaldi A, Kwee I, et al. Two main genetic pathways lead to the transformation of chronic lymphocytic leukemia to Richter syndrome. Blood 2013;122:26732682.

51. Tsimberidou AM, O'Brien S, Khouri I, et al. Clinical outcomes and prognostic factors in patients with Richter's syndrome treated with chemotherapy or chemoimmunotherapy with or without stem-cell transplantation. J Clin Oncol 2006;24:2343-2351.

52. Borthakur G, O'Brien S, Wierda WG, et al. Immune anaemias in patients with chronic lymphocytic leukaemia treated with fludarabine, cyclophosphamide and rituximab: incidence and predictors. Br J Haematol 2007;136:800-805.

53. Dearden C, Wade R, Else M, et al. The prognostic significance of a positive direct antiglobulin test in chronic lymphocytic leukemia: a beneficial effect of the combination of fludarabine and cyclophosphamide on the incidence of hemolytic anemia. Blood 2008;111:1820-1826.

54. Moreno C, Hodgson K, Ferrer G, et al. Autoimmune cytopenia in chronic lymphocytic leukemia: prevalence, clinical associations, and prognostic significance. Blood 2010;116:4771-4776. 